\section{Paulo Freire: da Teoria à Prática}

Escrever esta resenha para a edição inaugural da Revista Pluri, Revista Eletrônica de Estudos Interdisciplinares, é uma missão duplamente desafiadora, porque de um lado temos uma revista que nasce da iniciativa de promover o intercâmbio acadêmico entre áreas de conhecimentos, de outro, temos uma obra de grande importância a ser resenhada, uma vez que traz uma abordagem sobre a prática docente embasada nos estudos do notório filósofo da educação, Paulo Freire.

Algumas palavras, ainda que breves, precisam ser ditas, em primeiro lugar, sobre a necessidade do estabelecimento de um diálogo interáreas, uma vez que o fazer científico se torna completo quando há uma multiplicidade de olhares sobre determinado objeto. No caso do objeto de estudo 'a educação', então, urge que múltiplos olhares se encontrem, que muitas cabeças se unam e que muitas teorias se entrelacem, a fim de que novos caminhos sejam trilhados para que, de fato, haja uma educação libertadora, como preconiza o mestre Paulo Freire.

No ímpeto de estabelecer uma ponte entre a Universidade e a escola, entre teoria e prática, as estudiosas freireanas, Profa. Dra. Maria Lucia M. Carvalho Vasconcelos e Profa. Dra. Regina Pires de Brito, organizam e apresentam ao público a obra intitulada Paulo Freire: da Teoria à Prática, uma edição da LiberArs, São Paulo, 2018. O livro é fruto do trabalho de diversos pesquisadores que têm se empenhado em transpor didaticamente a teoria freireana para a melhora da qualidade da prática docente, tomados pela inquietacão sobre como e em que medida é possível "identificar, nas práticas pedagógicas de professores de opção democrática, o embasamento freireano" (Vasconcelos \& Brito, 2018, p. 16).

Como professor de opção democrática, podemos entender o professor que, de acordo com os conceitos do mestre Paulo Freire, assume uma postura de 'falar com' e não 'falar para' o aluno, numa relação interacional em que prevalece o diálogo entre quem ensina e quem aprende.

A organização da coletânea partiu dos conceitos apresentados no livro Pedagogia da Autonomia: saberes necessários à prática docente, e se estrutura em 13 capítulos, constituídos da seguinte forma: 1. discussão teórica acerca de um conceito da obra freireana e 2. relato e/ou sugestão de experiência didática, decorrente do conceito teórico apresentado no item 1, que se propõe a subsidiar o professor de Língua Portuguesa da Educação Básica.
Prof. ${ }^{a}$ Dr. ${ }^{a}$. Nelci Vieira de Lima

Doutorado em Língua

Portuguesa pela Pontifícia

Universidade Católica de

São Paulo, Pós-doc em

Linguística, pelo PNPD/

CAPES, no Programa de

Mestrado em Linguística da

Universidade Cruzeiro do Sul

e, atualmente, professora do

curso de Letras, modalidade

EaD, na Universidade

Cruzeiro do Sul.

Email: nevieira@gmail.com 
O capítulo 1 parte dos conceitos de autoridade, decisão e responsabilidade, discute a relação entre eles e leva o leitor à percepcão de que tais conceitos constituem-se como três pilares da educação democrática. Em relação à autoridade, as autoras a distinguem do autoritarismo e conclamam o professor à compreensão de seu papel de liderança em sala de aula, lembrando que a responsabilidade emana da autoridade. Como parte prática, o capítulo apresenta e analisa uma atividade de realização de um seminário, proposta de um livro didático. A análise contribui para a percepção de como o trabalho em grupo pode ser o caminho para o exercício da autonomia responsável e da autoridade.

O capítulo 2 discute o conceito de ideologia, visto como "central da compreensão da prática docente em qualquer nível e em qualquer desdobramento possível ou imaginável do ensino" (Ibid., p. 35). Para a autora do capítulo, o conceito de ideologia parece não estar sendo tratado como deveria nos dias de hoje e, por isso, merece maior atenção e esclarecimento. O capítulo conclama os professores à tomada de consciência e posicionamento crítico, uma vez que educar não é e jamais será um ato neutro, uma vez que a própria postura de neutralidade, defendida por muitos, é também uma postura ideológica. Como parte prática, o capítulo apresenta uma sugestão de sequência didática que envolve a produção da redação escolar, como forma de oportunizar aos alunos uma prática significativa de leitura e escrita. $\mathrm{Na}$ visão da autora do capítulo, a incumbência do ensino da leitura e escrita, muitas vezes, se centraliza na mão do professor de Língua Portuguesa, por imposição de um currículo escolar que fragmenta as práticas de ensino, por isso, a proposta é, antes de tudo, tornar significativas as aulas de redação, de forma que o aluno seja motivado a escrever, obedecendo a uma proposta que deixa clara a função social da escrita e a intenção comunicativa do autor do texto. A proposta sugerida traz à tona um projeto de ensino de escrita que contempla a criticidade dos alunos e a visão de mundo dos alunos a partir de temas que contemplem o eixo dos temas transversais, propostos pelos Parâmetros Curriculares Nacionais.

O terceiro capítulo parte de um ponto fulcral na obra de Paulo Freire, o respeito e a valorização do outro que vê o aluno como agente de sua aprendizagem, capaz de assumir-se como sujeito social e histórico. Nessa perspectiva, há que se respeitar a bagagem cultural e social do aluno, para que, a partir dela, ele seja motivado a construir seu saber, especialmente, no âmbito da aprendizagem de línguas. Como proposta de prática, as autoras apresentam uma sugestão de trabalho com músicas em contextos multiculturais que atendam às diversas modalidades de ensino da língua: "Português língua não-materna, Português língua-estrangeira, Português língua de Acolhimento (como no caso de indivíduos em situação de refúgio) ou Português Língua de Herança (no caso de filhos de falantes que residem em países que não adotam o português como oficial)" (Ibid. pág. 54).

O quarto capítulo parte do conceito de "apreensão da realidade", tomando a acepção do vetor apreender que extrapola o aprender, tendo em vista se tratar de "captar a essência ou a concretude do objeto" (Ibid., p.66), em uma prática capaz de transformar a realidade do aluno. A parte prática do capítulo volta-se ao ensino da literatura, por meio de uma proposta que vai além de um ensino mecânico de memorização de características de períodos literários e datas. A proposta sugere atividades de leitura de textos literários que proporcionem uma experiência significativa aos alunos, de modo a se desenvolverem cognitiva e criticamente, de maneira a aprender a realidade.

O quinto capítulo extrapola a teoria e a prática e, persuasivamente, convoca o leitor a participar da mudança social tão necessária ao "desenvolvimento do ser humano em todos os ciclos da vida" (Ibid., p. 79). Seguindo a linha de pensamento freireana, defende-se, no capítulo, que docentes e discentes, imbuídos da 
consciência de estar no mundo, possam atuar e transformar esse mundo, por meio de uma práxis reflexiva. Fato indubitável é de que o mundo carece de mudanças profundas que tragam mais sensibilidade e humanização às relações que por influência dos avanços tecnológicos e com a obscuridade de nossos dias parecem ter se endurecido. Diante disso, o capítulo torna-se bastante pertinente ao apresentar, como prática docente democrática, atividades de linguagem que se aportam em um elemento da modernidade e do cotidiano dos alunos: a tecnologia. Os relatos de experiência vão da produção de vídeo-minuto a partir da leitura de uma obra literária até uma visita orientada ao Museu da Língua Portuguesa, como texto sincrético cuja leitura é dinâmica e hipertextual. Ao leitor-docente, o capítulo é uma amostra de como é possível trazer para as aulas de Língua Portuguesa a midiabilidade do cotidiano dos alunos, cumprindo, assim, o papel de educar para as mídias e para a informação, desenvolvendo nos alunos letramentos múltiplos, tão necessários às práticas sociais modernas.

O capítulo 6 trata de um exercício primordial em todas as relações humanas, quanto mais naquelas que envolvem o ambiente escolar e a prática pedagógica: o exercício de escuta. O exercício da escuta é condição sine qua non para o estabelecimento da horizontalidade nas relações - gestor-professor, professorprofessor, professor-aluno, aluno-aluno, escola-comunidade - construindo, assim, uma escola democrática, em que a aprendizagem seja fator de mudança social. O capítulo apresenta uma prática pedagógica realizada a partir de um exercício, trazido no Material de Apoio ao Currículo do Estado de São Paulo, em que os alunos foram convidados a participar de um projeto de 'Fotojornalismo' cuja realização se fez com apoio de seus aparelhos celulares, de forma que a tecnologia fosse convertida a um instrumento de aprendizagem. $O$ projeto trouxe à tona também a cooperação que envolve o trabalho em grupo, a autonomia e o saber escutar o outro, uma vez que durante a preparação do projeto e a escolha dos temas, os alunos se posicionaram e foram ouvidos.

O capítulo 7 trata do conceito de criticidade e também apresenta considerações sobre o ensino da literatura. Já o capítulo 8 parte do princípio de que conhecer o passado contribui para a escrita do presente e traz um relato sobre o trabalho envolvendo leitura e produção textual de biografias, como forma de levar o aluno a tomar "consciência de sua condição identitária" e a resgatar a história do povo negro, conforme a Lei 10.639/03, que institui a obrigatoriedade do ensino da cultura e história africanas nas escolas brasileiras. Também o capítulo 9 elege a questão étnica-racial como ponto de partida para a reflexão sobre a prática pedagógica calcada nas concepções freireanas, uma vez que, conforme argumentam as autoras, grande parte do contingente de alunos atendidos pela escola brasileira são pardos ou pretos.

Os demais capítulos enfatizam as abordagens brevemente descritas e comentadas até aqui. Assim, o capítulo 10 trata dos conceitos de bom senso e ética, o 11 apresenta uma prática pedagógica de construção de um jornal, o que instiga os alunos à reflexão sobre a construção do discurso jornalístico e o papel do jornalista na sociedade. 0 capítulo 12 retoma a questão da autonomia do aluno e dos saberes necessários às práticas educativas e, por fim, o capítulo de encerramento traz para a cena da discussão, a aula, como prática dialógica que ressignificada traz o aluno para o centro do processo de ensino-aprendizagem.

Tendo em vista que teoria e prática são duas faces da mesma moeda, embora seja comum ouvir do docente a frase "falar é fácil, fazer é difícil", é preciso quebrar essa dicotomia, ou mesmo esse "preconceito", por meio do estabelecimento de uma ponte entre Universidade/ Escola. Uma vez que a teoria vem da prática reflexiva e não o contrário, torna-se ideal que caminhem juntas, seguindo essa ordem: prática reflexiva e embasada teoricamente que gera novas teorias e que modifica velhas práticas. Nesse sentido, a leitura do livro que aqui se apresenta torna-se imperativa àqueles que tri- 
Iham os caminhos das licenciaturas e, também, para aqueles que já exercem a prática docente, pois os capítulos, um a um, trazem reflexões teóricas e relatos e/ou sugestões de práticas docentes que nelas se embasam, a fim de que o ideal aconteça: uma aprendizagem significativa a partir de um ensino democrático, em que o aluno seja o protagonista e o professor, aquele que munido de autoridade, mas sem autoritarismo, o guia pela trilha do conhecimento. 